\title{
SOBRE AS MARGENS DE UMA TEORIA: A LINNGUA E AS LENDAS GERMÂNICAS
}

\section{Stefania Henriques}

(iD) https://orcid.org/0000-0002-4517-0121

Como citar este artigo: HENRIQUES, S. Sobre as margens de uma teoria: a língua e as lendas germânicas. Todas as Letras - Revista de Lingua e Literatura, São Paulo, v. 22, n. 2, p. 1-13, maio/ago. 2020. DOI 10.5935/1980-6914/eLETDO2013376

Submissão: maio de 2020. Aceite: junho de 2020.

Resumo: Neste artigo, analisamos os manuscritos sobre as lendas germânicas com o objetivo de questionar a classificação de "marginal" dada a esses estudos. Para isso, partimos de uma reflexão sobre a própria natureza da linguagem no arcabouço teórico saussuriano e sobre a noção de "margem" nesse contexto.

Palavras-chave: Ferdinand de Saussure. Manuscritos. Lendas germânicas. Semiologia. Língua. 


\section{INTRODUÇÃO}

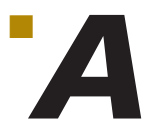

ideia de propor uma reflexão sobre as margens na teoria saussuriana nasceu de dois momentos da minha formação como pesquisadora: o primeiro refere-se à publicação da obra As bordas da linguagem, organizada pela professora doutora Eliane Silveira e publicada em 2011, na qual há um artigo de Claudine Normand, intitulado "Saussure: uma epistemologia da Linguística", que foi essencial para o meu desenvolvimento como pesquisadora. O segundo momento, por sua vez, refere-se ao I Colóquio Saussure in Focus, que ocorreu em 2019 na Universidade Federal de Uberlândia (UFU) e foi organizado pelo Grupo de Pesquisa Ferdinand de Saussure (CNPq). Nessa ocasião, participei de uma mesa-redonda intitulada "Saussure das margens", juntamente com o professor doutor Marcen de Souza e a professora doutora Thayanne Lima.

A palavra "margem", à primeira vista, não parece oferecer problemas. Dentre as acepções apresentadas pelo Dicionário Priberam (2020), temos as seguintes: "1. Linha ou zona que limita um espaço. = Beira, borda, orla; 2 . Faixa de terreno que fica de um dos lados de uma extensão de água; 3. Cercadura [...]". Além dessas, temos, em português brasileiro, a expressão "estar à margem", que significaria "ser deixado de lado" e a forma derivada "marginal", que possui uma acepção marcada pela valoração social: algo ou alguém que está à margem da sociedade; excluído; desrespeita leis, costumes e valores sociais. Neste artigo, será discutida a noção de "margem" aplicada à constituição de uma ciência, no sentido de "delimitação" e de "marginal", como aquilo que é excluído, que extrapola os limites de algo preestabelecido convencionalmente e que, por tal motivo, é valorado de maneira negativa.

Não é, obviamente, a primeira vez que essas palavras são utilizadas no âmbito científico. A partir da década de 1970, por exemplo, surge no Brasil a expressão "literatura marginal", que diz respeito às manifestações literárias de indivíduos excluídos da sociedade, que não somente diferem em sua forma de fazer literatura e de se utilizar da linguagem, como também em suas concepções políticas e comportamentos sociais, distintos daqueles que são aceitos e impostos pela ordem social vigente.

Nessa perspectiva, esse termo e seus sinônimos também já foram largamente utilizados pela recepção da teoria saussuriana. O Curso de Linguística Geral $(1916)^{1}$, resultado da edição, realizada por Charles Bally e Albert Riedlinger, de anotações dos alunos que participaram dos cursos realizados na Universidade de Genebra entre 1907 e 1911 e de notas autógrafas de Ferdinand de Saussure, ocupa um lugar central - de autoridade - justamente pelo fato de ter sido responsável pela instituição da Linguística Moderna. Em contrapartida, o surgimento dos manuscritos saussurianos a partir da década de 1950 e, mais recentemente, no final do século $\mathrm{XX}^{2}$, recebeu, durante muito tempo, o estatuto de marginal em relação à ordem instituída, ou seja, o CLG ${ }^{3}$.

2 De acordo com Marchese (2003), isso se dá em quatro momentos: em janeiro de 1955, a família de Saussure doa vários manuscritos para a Biblioteca de Genebra. Em novembro do mesmo ano, Mme. Bally doa os manuscritos que estavam em posse de Charles Bally. Em 1968, os filhos de Ferdinand de Saussure vendem alguns manuscritos, por intermédio de Roman Jakobson, para Harvard. E, por fim, em 1996 novos manuscritos são encontrados na casa de campo de Saussure (cf. MARCHESE, 2003, p. 338).

3 Obviamente, há posições divergentes nessa discussão. Simon Bouquet, por exemplo, partilha da concepção de que é nos manuscritos que pode ser encontrada a verdadeira teorização de Ferdinand de Saussure, enquanto no CLG, o que se tem é uma 
Essa marginalidade foi estendida ao conteúdo desses documentos. Sabe-se, por exemplo, que Saussure desenvolveu estudos sobre as lendas germânicas entre 1903 e $1910^{4}$, ou seja, praticamente ao mesmo tempo em que se dedicava aos três cursos de linguística geral. O conteúdo desse conjunto de manuscritos foi tratado, por vários estudiosos, como algo marginal nas elaborações do linguista suíço, chegando, inclusive, a ser classificado como bizarro por Claude Zilberberg (1997).

Neste artigo, pretendemos questionar a classificação de "marginal" dada a esses estudos, partindo de uma reflexão sobre a própria natureza da linguagem no arcabouço teórico saussuriano e sobre a noção de margem nesse contexto. Dessa forma, nossa argumentação será dividida em três partes: na primeira, investigaremos o que é a linguagem na perspectiva saussuriana, trazendo à tona a instituição da língua como objeto de estudo da linguística; na segunda parte, por sua vez, será realizado um percurso pela recepção dos manuscritos sobre as lendas; e, por fim, na terceira parte, faremos uma reflexão acerca da potencialidade daquilo que é considerado marginal, analisando esses manuscritos e destacando, principalmente, as relações entre a lingua e a lenda.

\section{UM LUGAR “ESTÁVEL” DENTRO DO MOVIMENTO: DA RELAÇÃo ENTRE LINGUAGEM E LÍNGUA}

Sabe-se que um dos aspectos que proporcionam a fundação da Linguística Moderna por Ferdinand de Saussure é a instituição da lingua como objeto de estudo. Concebida como um sistema de signos arbitrários, que só adquirem valor porque se relacionam uns com os outros, a língua está contida em um fenômeno heterogêneo e mais geral, que é a linguagem, na qual também se encontra a fala.

No capítulo intitulado "Matéria e tarefa da Linguística: suas relações com as ciências conexas", o linguista suíço elenca as tarefas da linguística e nos induz a diferenciar o que é a matéria dessa ciência e qual o seu objeto de estudo. Sobre a matéria, ele afirma que ela

[...] é constituida inicialmente por todas as manifestações da linguagem humana, quer se trate de povos selvagens ou de nações civilizadas, de épocas arcaicas, clássicas ou de decadência, considerando-se em cada período não só a "linguagem correta e a bela linguagem", mas todas as formas de expressão (SAUSSURE, 2012 [1916], p. 37).

A natureza heteróclita da linguagem teria duas consequências principais: a primeira é escapar "muitas das vezes à observação" (p. 37), e a segunda, como Saussure já indica no desenvolvimento deste capítulo, é possibilitar que ela seja tomada também por outras disciplinas que não a linguística. Assim, é inegável a existência de reflexões sobre a linguagem na etnografia, na antropologia, na sociologia, na filosofia etc., tendo em vista que ela se faz presente, por exemplo, em todas as manifestações sociais e culturais de um povo. leitura de Bouquet (1997).

4 Esses manuscritos estão compreendidos em 18 cadernos, além de várias folhas avulsas, totalizando aproximadamente 1.400 páginas, e foram doados à Biblioteca de Genebra em 1955 pela família de Ferdinand de Saussure (cf. STAROBINSKI, 1974, p. 9). 
Mas como conceber, então, uma ciência que se dedique inteiramente ao estudo do fenômeno linguístico? É nesse ponto que o linguista explicita a tarefa da linguística. De acordo com ele, essa ciência deve

a) fazer a descrição e a história de todas as línguas que puder abranger, o que quer dizer: fazer a história das famílias de línguas e reconstituir, na medida do possível, as línguas-mães de cada família;

b) procurar as forças que estão em jogo, de modo permanente e universal, em todas as linguas e deduzir as leis gerais às quais se possam referir todos os fenômenos peculiares da história;

c) delimitar-se e definir-se a si própria (SAUSSURE, 2012 [1916], p. 37).

Nesse sentido, considerando que a linguagem "não se deixa classificar em nenhuma categoria de fatos humanos, pois não se sabe como inferir sua unidade", a terceira tarefa elencada por Saussure seria a mais urgente e importante: "delimitar-se e definir-se a si própria". Essa também parece ser a tarefa que mais o incomodava. Na célebre carta a A. Meillet, datada de 1894, ou seja, cerca de 13 anos antes dos cursos ministrados em Genebra, Saussure (apud FEHR, 1996, p. 15-16, tradução nossa) afirma:

Sem cessar, a absoluta inépcia da terminologia corrente, a necessidade da reforma e de mostrar para isso que espécie de objeto é a língua em geral vem estragar meu prazer histórico, embora eu não tenha desejo mais caro do que o de não ter de ocupar-me da língua em geral ${ }^{5}$.

O prazer histórico de Saussure, relacionado à primeira tarefa elencada por ele anos mais tarde, deveria ser suspenso para que a terminologia fosse revista e adequada. Em sua perspectiva, não parecia ser possivel investigar o fenômeno linguístico sem antes delimitar o objeto de estudo dessa nova ciência. Como aponta Normand (2011, p. 15), o linguista procurava estabelecer uma epistemologia que não seria aplicada a todas as ciências, mas sim a "um domínio de pesquisa específico, a Linguística, em um determinado momento de seu desenvolvimento".

Ademais, deve-se ressaltar que há uma distinção importante entre "matéria" e "objeto". De acordo com De Mauro (1967), a matéria, para Saussure, se constitui enquanto o conjunto de todos os fatos pertencentes à linguagem, que podem ser considerados como linguísticos. A língua, nesse contexto, é o objeto da linguística e está reservada:

[...] à matéria investigada na medida em que é produzida e ordenada de forma sistemática no desenvolvimento de uma pesquisa; os objetos são, portanto, os objetivos da pesquisa. A ambiguidade que se poderia encontrar na utilização do termo "objeto" nesse sentido (já que a regra quer que essa palavra se aplique às coisas observadas ou pensadas) é só aparente. De fato, as coisas não existem para nós como objetos que enquanto tais foram previamente determinados como resultados de pesquisa (DE MAURO, 1967, p. 415, tradução nossa) ${ }^{6}$.

5 No original: "Sans cesse l'ineptie absolue de la terminologie courante, la nécessité de la réforme, et de montrer pour cela quelle espèce d'objet est la langue en général, vient gâter mon plaisir historique, quoique je n'aie pas de plus cher voeu que de n'avoir pas à m'occuper de la langue en général".

6 No original: "[...] à matière traitée dans la mesure où elle a été produite et ordonné sous forme systématique au cours de la recherche; les objets sont donc les objectifs de la recherche. L'ambiguïté que l'on pourrait rencontrer dans l'utilisation du terme 'objet' en ce sens (puisque la règle veut que ce mot s'applique aux choses observées ou pensées) n'est qu'apparente. En fait, les choses n'existent pour nous comme objets qu'en tant qu'elles aient été au préalable déterminées comme résultats de recherche". 
Só há objeto após o seu estabelecimento por meio de procedimentos científicos. Tratar a língua como objeto da linguística é, desse modo, colocá-la como um objetivo da pesquisa. É nesse ponto, então, que trazemos à tona a famosa afirmação de que "Bem longe de dizer que o objeto precede o ponto de vista, diríamos que é o ponto de vista que cria o objeto" (SAUSSURE, 2012 [1916], p. 39). Considerando que a linguagem é heteróclita e abarca fenômenos distintos, muitas vezes dificeis de serem delimitados, faz-se necessária uma escolha metodológica: determinar o ponto de vista que será abordado, para, a partir dele, criar o objeto.

Definir a língua como objeto de estudo, então, é a operação que torna possivel o estabelecimento da linguística enquanto ciência. Mas, como afirma Normand (2011, p. 19), a delimitação desse objeto não implica uma exclusão, pois

Cada ponto de vista define um domínio de observáveis, segundo uma epistemologia, neste estágio positivista, que só é redutora, caso se interprete como uma exclusão definitiva o que é somente um gesto de delimitação necessário em um determinado momento, para esclarecer as confusões e retificar o método.

$\mathrm{E}$ aqui retomamos o título deste tópico: não seria a língua um lugar estável em meio ao movimento, que é a linguagem? Se esta é caracterizada por abarcar fenômenos distintos, relacionados aos aspectos culturais e sociais de um povo, não podemos considerá-la como um rio que, além das duas margens que já possui, também tem uma terceira, que é aquela em que a língua se encontra?

A menção à terceira margem não é ao acaso. No conto de Guimarães Rosa "A terceira margem do rio", publicado em 1962, encontramos a história de um homem "cumpridor, ordeiro, positivo" que manda fazer para si uma canoa e decide nela embarcar para permanecer no rio, "de meio a meio, sempre dentro da canoa, para dela não saltar, nunca mais" (ROSA, 1988, p. 79). Correndo o risco de um delírio, a canoa não poderia ser a teoria linguística, que tenta permanecer estável, de meio a meio, delimitando, em meio ao movimento contínuo e heteróclito, um lugar estável?

Se há algo de pertinente nessa comparação com o conto de Guimarães Rosa, a possibilidade de se falar de temas ou documentos marginais nas elaborações saussurianas se torna insustentável, porque apesar de estar na canoa e tentar uma estabilidade em meio ao movimento, há uma série de aspectos que se misturam e com os quais a língua tem contato a todo instante. É a partir dessa perspectiva que pretendemos pensar a questão das margens nas elaborações saussurianas, considerando que os manuscritos sobre as lendas, vistos por muitos autores como "marginais", estão, na verdade, intrinsecamente relacionados à teoria linguística.

Antes, entretanto, teceremos breves considerações acerca da recepção desses documentos pelos estudiosos da fortuna saussuriana, ressaltando o debate estabelecido entre D’Arco Silvio Avalle e Rudolf Engler.

\section{DA RECEPÇÃO DO “MARGINAL": OS MANUSCRITOS SOBRE AS LENDAS E A LINGUística}

Como já dito na introdução deste artigo, o estudo sobre as lendas germânicas foi desenvolvido entre 1903 e 1910, ou seja, parcialmente concomitante aos cursos de linguística geral ministrados por Saussure entre 1907 e 1911. A existência desses manuscritos já é conhecida desde a primeira doação, realizada 
pela família do linguista, em 1955, tendo sido catalogados por Robert Godel e arquivados na Biblioteca de Genebra como Ms. Fr. 3958 e Ms. Fr. 39597.

Apesar de terem sido desenvolvidos no mesmo período que os cursos e de já serem conhecidos pelos estudiosos da fortuna saussuriana desde a década de 1950, os manuscritos sobre as lendas só passaram a ser, de fato, estudados, a partir de 1970, com a publicação do artigo "La sémiologie de la narrativité chez Saussure” (1973) de D’Arco Silvio Avalle. Nele, há uma transcrição de alguns trechos desses documentos ${ }^{8}$, com o objetivo de confrontar seu conteúdo com as elaborações presentes no CLG e questionar a noção de Semiologia como ciência geral dos signos.

Como veremos no decorrer deste artigo, Saussure retoma em vários momentos sua conceituação sobre a língua e seu funcionamento ao teorizar sobre a narrativa lendária. Para Avalle (1973, p. 44, tradução nossa), entretanto, as comparações realizadas pelo linguista não seriam convincentes, pois "A impressão que se tem é que elas são o fruto mais de uma extrapolação das propriedades da 'lingua' à lenda do que uma análise visando estabelecer as bases de uma ciência unitária"9.

Para Avalle (1973), desse modo, não haveria uma relação de equidade no funcionamento desses dois sistemas - lingua e lenda -, apesar de Saussure afirmar isso em vários momentos. Como aponta Prosdocimi (1983), Avalle conduz seu leitor a cindir o pensamento saussuriano por quatro: haveria um Saussure do Mémoire, um do CLG, um dos anagramas e, por fim, um Saussure das lendas. Essa cisão não foi incomum na época, sofrendo variações de acordo com os documentos saussurianos analisados. Em 12 e 13 de abril de 1974, por exemplo, ocorre o colóquio Les deux Saussure, em que se defendia a existência de um "Saussure diurno" - aquele da linguística - e um "Saussure noturno" - dos anagramas e das lendas. Ainda nessa época, surgem outras divisões das elaborações saussurianas, como entre um Saussure comparatista versus um Saussure generalista (cf. REDARD, 1978), que se refere aos estudos desenvolvidos pelo linguista no século XIX, dos quais o mais reconhecido foi o Mémoire sur le système primitif des voyelles indo européennes, e às elaborações saussurianas presentes no CLG.

Posicionando-se contrariamente a Avalle (1973), Rudolf Engler publica o artigo Sémiologies saussuriennes: 1. De l'existence du signe (1974-1975). Nele, acusa o crítico literário de interpretar erroneamente os manuscritos das lendas germânicas e editá-los de maneira a comprovar sua tese da não relação entre a língua e a lenda e, ainda, da negação da existência do símbolo, tal como ele é concebido nesse material. Para Engler (1974-1975), Avalle (1973) é tendencioso em sua análise, além de desconsiderar dados cronológicos importantes. De acordo com ele

Não há extrapolação, mas antes um encontro sobre um ponto preciso do plano semiológico entre as duas pesquisas, e a teoria do signo lendário resulta de análises filológicas de detalhes factuais, essa é a nossa primeira conclusão (ENGLER, 1974-1975, p. 61, tradução nossa) ${ }^{10}$.

\footnotetext{
Para um detalhamento desses arquivos, conferir Henriques (2019).

Avalle utiliza trechos dos cadernos 3958.4 e 3958.6 e 3959.10 e 3959.11.

No original: "L'impression qu'on tire est qu'elles sont le fruit bien plus d'une extrapolation des propriétés de la 'langue' à la légende, que d'une analyse visant à jeter les bases d'une science unitaire".

10 No original: "Il n'y a pas extrapolation, mais bien plutôt rencontre sur un point précis du plan sémiologique entre les deux recherches, et la théorie du signe légendifère découle d'analyses philologiques de détails factuels, telle est notre première conclusion".
} 
Desse modo, haveria uma uniformidade na teoria saussuriana, tendo em vista que para se analisar a lenda, deve-se considerar, como meio de análise, a língua. Como vimos no tópico anterior, isso está em conformidade com o que é explicitado no CLG, tendo em vista que Saussure afirma o primado da língua em relação aos outros sistemas semiológicos. Há, portanto, uma diferença essencial entre os posicionamentos de Avalle (1973) e Engler (1974-1975): o primeiro defende uma pluralidade na teoria saussuriana, considerando que as lendas e a língua não são comparáveis umas às outras. O segundo, por sua vez, afirma que a comparação entre os dois sistemas é pertinente justamente porque Saussure visava à Semiologia e, desse ponto de vista, ambos os sistemas são semiológicos e possuem o mesmo funcionamento:

[...] não há nenhuma diferença essencial entre semiologia linguística e semiologia mitográfica, e as diferenças existentes concernem ao ponto de vista de uma parte, à natureza particular do objeto estudado de outra, e que elas são conciliáveis (ENGLER, 1974-1975, p. 59, tradução nossa) ${ }^{11}$.

Nesse contexto, a concepção de Engler (1974-1975) é a que parece mais sensata e reverbera, até hoje, nos trabalhos de estudiosos que se dedicam aos manuscritos saussurianos. Isso porque não se pode esquecer que o conceito de semiologia abarca o fenômeno mais geral da linguagem, contendo, por exemplo, os estudos dos gestos de polidez, de costumes etc. (cf. SAUSSURE, 2012 [1916]). A língua, então, é um dos sistemas semiológicos, sendo considerado por Saussure como o "sistema semiológico por excelência", pois contém todas as características para tal.

Isso justifica, por exemplo, o fato de que, apesar de os manuscritos sobre as lendas possuírem várias menções ao funcionamento da língua, o mesmo não se dá no CLG ou nos manuscritos de linguística. Aqui, lembramo-nos das palavras de Silveira (2013, p. 47), segundo a qual cada uma das empreitadas saussurianas - tanto no âmbito comparatista quanto no mitográfico e anagramático - "resultaram em alguma reflexão sobre o caráter geral do objeto da linguística [...]”.

No próximo tópico, alguns excertos dos manuscritos sobre as lendas serão analisados com o objetivo de tentar entrever as reflexões que podem contribuir para a elucidação de questões linguísticas. De igual modo, propomos também uma reflexão sobre a potencialidade daquilo que é considerado marginal nas elaborações saussurianas.

\section{DA POTENCIALIDADE DO “MARGINAL": AS LENDAS E A LÍNGUA}

Os manuscritos sobre as lendas possuem, aproximadamente, 1.400 páginas, dentre as quais grande parte é composta por considerações históricas e comparações entre personagens das lendas e personagens da história dos povos, principalmente do povo burgúndio. O interesse de Saussure pela história não é uma novidade para os estudiosos de sua fortuna teórica. Além de ter tido toda a sua formação acadêmica no século XIX, auge da Gramática Histórico-Comparativa, vimos no tópico 1 a carta enviada a Meillet, na qual se lê que a tarefa de mostrar ao linguista o que ele faz estragava o seu prazer histórico.

11 No original: "[...] n'y a aucune différence essentielle entre sémiologie linguistique et sémiologie mythographique, que les différences existantes tiennent au point de vue d'une part, à la nature particulière de l'objet étudié de l'autre, et qu'elles sont conciliables". 
Dito isso, o primeiro ponto a ser ressaltado é que o estudo desenvolvido por Saussure sobre as lendas é motivado, em primeira instância, pelo seu aspecto histórico. Em 1904, em uma comunicação proferida à Société d'Histoire et Archéologie de Génève ${ }^{12}$, o linguista afirma:

Assentados primeiro na bacia do Elba, depois no Wurtemberg atual, os burgúndios, antes de se fixarem em nossas terras, formaram no médio Reno, em torno de Worms, um Estado efêmero, cuja lembrança, embelezada pela poesia, transmitiu-se de geração em geração nas narrativas e canções épicas referentes aos Niebelungen (SAUSSURE, 1922 [1904], p. 606, tradução nossa) ${ }^{13}$.

Os burgúndios, povo ao qual Saussure se refere, teriam vivido por volta de 400 a.C. e seu império efêmero teria durado até 437 a.C. De acordo com Herman (1999), após terem sido atacados pelos hunos, os burgúndios foram praticamente extintos, sendo que aqueles que sobreviveram se distribuíram pelo território europeu. Em virtude do seu fim trágico, várias narrativas começaram a ser contadas pelos sobreviventes, o que em determinado momento da história adquiriu um caráter mitológico, originando, assim, a lenda dos Nibelungos.

O linguista suíço, em suas pesquisas históricas, percebeu que, apesar da curta duração desse império, vários nomes próprios e geográficos foram transmitidos durante séculos, sendo encontrados até o início do século XX em algumas regiões suíças e francesas. Por outro lado, a história desse povo carecia de detalhes, tendo em vista que só havia duas passagens nas Chroniques, o que fez com que Saussure se interessasse pela análise da lenda dos Nibelungos:

$\mathrm{Na}<\mathrm{A}>$ concepção da crítica corrente, na qual tudo se ligaria efetivamente a $<$ repousaria no $>$ reino de Worms, leva, se <queremos $>$ prestar atenção a isso, a pressuposições<conclusões $>$ históricas duas vezes mais ousadas do que as nossas, sob o pretexto de permanecer fiel aos textos. Que extraordinário tesouro para a história não seria teríamos nos Nibelungenlied? Toda a vida do pequeno reino burgúndio de 435, cuja existência é, por outro lado, apenas certificada por duas menções nas Crônicas, estaria aí, sob nossos olhos, e com incomparável profusão de detalhes. Um furo da história seria substituído por uma fonte abundante. Eis o que desperta certa desconfiança e leva a pensar que: ou toda essa copiosa lenda é puro fruto de invenção, o que é improvável, ou então se ela tem o umum fundo histórico, todas as probabilidades são que ocorra sobre um fundo histórico absolutamente conhecido e coletado pelos cronis<tas>erônieas, paralelamente ao que ela própria oferece. Assim, o olhar se dirige apenas para o reino de reino da Burgúndia foi sério <teve um passado notório $><q u e$ nunca $><q u e$ oferece um corpo para a história $>$, o reino de Lyon, tão logo se admita que o fundo da narrativa não é fictício (SAUSSURE, Ms. Fr. 3958-2, f. 4, tradução nossa) ${ }^{14}$.

12 Les Burgondes et la langue burgonde en pays romaine (15 de dezembro de 1904).

13 No original: "Établis d'abord dans le bassin de l'Elbe, puis dans le Wurtemberg actuel, les Burgondes, avant de se fixer dans nos contrées, avaient formé sur le Rhin moyen, autour de Worms, un État éphémère, dont le souvenir, embelli par la poésie, s'est transmis de génération en génération dans les récits et les chansons épiques relatifs aux Nibelungen".

14 No original: "Đans la<La> conception qui est celle de la critique courante, et où tout se rapporterait effectivement au <reposerait sur le> royaume de Worms, aboutit, si l'on <veut bien> y prendre garde, à des présomptions <conclusions> historiques deux fois plus hardies que les nôtres sous prétexte de rester fidèles aux textes. Quel extraordinaire trésor pour l'histoire serait n'aurions-nous pas alors dans le Nibelungenlied? Toute la vie du petit royaume burgonde de 435, autrement à peine certifié dans son existence par deux mentions de Chroniques, serait là sous nos yeux, et avec une profusion de détails incomparable ! Un trou de l'histoire serait remplacé par une abondante <source>. Voilà qui éveille quelque défiance, et qui amène au moins à 
Considerando, então, a existência da lenda dos Nibelungos e sua relação com a história do povo burgúndio, a investigação dessa narrativa por Saussure adquire especial importância pela possibilidade de preencher uma lacuna histórica com uma fonte abundante. Contudo, isso não seria uma tarefa fácil. Como dito anteriormente, os eventos históricos relacionados ao povo burgúndio ocorreram por volta de quatro séculos a. C. e foram transmitidos oralmente, de geração em geração, e em territórios diversos, por aproximadamente oito séculos ${ }^{15}$, até terem a sua primeira versão escrita.

Nesse sentido, apesar de empreender uma pesquisa de cunho histórico, realizando a comparação entre personagens e eventos históricos e lendários, Saussure se depara com um funcionamento específico da narrativa oral - algo que ela oferece por si mesma -, que deixa entrever não somente uma forma de transmissão da história, como também a relação estabelecida entre a linguagem (lingua + fala) e a memória. Nesse ponto, é conveniente retomar nossa analogia com o conto de Guimarães Rosa: ao colocar a canoa na terceira margem do rio, mesmo que tente delimitar um espaço, um objetivo de estudo, nesse caso, histórico, o linguista ainda assim se depara com toda sorte de fenômenos que, apesar de distintos, relacionam-se e fazem parte da linguagem.

No trecho a seguir é possivel acompanhar o raciocínio de Saussure no que concerne às mudanças no enredo das lendas e à indicação de que há um funcionamento que lhe é específico e influencia a transmissão da história:

[...] Exemplo da nulidade.

Versão a. - O rei X tem 3 filhos: Gunther, Gêrnot e Gîselher. Esses filhos têm um primo chamado Hagen.

Versão b. - O rei X tem 3 filhos: Gunther, Gêrnot e Hagen.

Sobre o que nós vamos escrever: Hagen tomou o lugar de Gîselher, ou Gîselher é desconhecido à [ ] Há todo um mundo nessa simples maneira ( pra na prática quase inevitável) de proceder.

Nada prova té aqui que o papel de Hagen não seja aquele que tem Gunther em outra versão, ou mesmo que não haveria uma confusão etc. <que não se poderia dizer de uma versão à outra que responde a um nome.> Fato a tomar: para comparar

Individuo a. qualidade de filho irmão de $X$

Nome: Hagen.

Se a lenda pega o capacete de Dietrich <Áquila> para lhe colocar na cabeça de Sigfrid, a esposa de Sigfrid para dar em casamento a Dietrich, o nome de Sigfrid para the dar a Gunther, não haverá mais nem Dietrich nem Sigfrid. Ora, é isso o que acontece em uma medida mais ou menos grande, e em uma medida em que não é permitido a ninguém [

se dire ceci: ou bien toute cette copieuse légende est un pur produit d'invention, ce qui est improbable, ou bien si elle court sur te un un fond historique toutes les chances sont pour qu'elle coure sur un fond historique absolument connu et recueilli par des chroniqu<eurs> throniques parallèlement à ce qu'elle offre elle-même. Ainsi le regard est dirigé vers le foyaume de seul royaume de Burgondiefut sérieux <a passé notoire ><qui a jamais ><qui offre un corps pour l'histoire, le royaume de Lyon, aussitôt que nous admettons que le fond du récit n'est pas factice.>".

15 Herman (1999) aponta que as primeiras formas escritas dessa lenda foram a Edda e a Völsungensaga. A primeira possui duas versões: a Edda poética e a Snorra Edda. Snorri Sturluson foi o responsável pela primeira escrita da Snorra Edda, que teria ocorrido por volta de 1200. Entretanto, em 1643 foi descoberto um manuscrito mais antigo, que teria sido utilizado por Sturluson para a confecção de sua versão. Esse manuscrito é chamado de Edda poética (cf. HERMAN, 1999, p. 25). No que concerne à Völsungensaga, não há uma autoria específica, mas sabe-se que ela foi escrita por volta de 1275 . Nela, são narrados os acontecimentos referentes à morte de Sigmund e ao nascimento de seu filho Sugurd. 
$<$ A questão não é saber se é provável que a lenda o faça. É unicamente constatar que se ela ofaz, ou se ela ofez, nós estamos na incapacidade absoluta de, mesmo sobre um capacete, de dizer que se trata da mesma pessoa, mas geralmente que essa pessoa é em parte constituída por seu capacete.> (SAUSSURE, Ms. Fr. 3958.8, f. 22, tradução nossa) ${ }^{16}$.

Nesse excerto, são vários os aspectos que permitem retomar as elaborações saussurianas sobre a linguística. O primeiro deles concerne ao fato de que há uma oscilação no nome dos personagens e nas suas características, atitudes etc. Essa oscilação traz consequências para todo o enredo, não permitindo a recuperação total dos dados históricos presentes na narrativa. Isso retoma de maneira inequivoca a teoria do valor, tal como é apresentada no CLG: "a língua é um sistema em que todos os termos são solidários e o valor de um resulta tão somente da presença simultânea de outros [...]" (SAUSSURE, 2012 [1916], p. 161). Ora, o que se tem na análise sobre os personagens lendários é justamente o fato de que aquilo que constituiu cada personagem são as características e ações a ele atribuídas no enredo. Desse modo, considerando a transmissão oral, tem-se que um mesmo personagem adquire estatutos diferentes em versões distintas da mesma lenda e o seu laço com o evento histórico fica, de certa maneira, apagado.

Ademais, Saussure (2012 [1916], p. 169) afirma que:

Aplicado à unidade, o princípio da diferenciação pode ser assim formulado: os caracteres da unidade se confundem com a própria unidade. Na língua, como em todo sistema semiológico, o que distingue um signo é tudo o que o constitui. A diferença é o que faz a característica, como faz o valor e a unidade.

Em qualquer sistema semiológico, são as diferentes características de um signo que o constituem: se um elemento da lenda sofre modificações, os valores dos outros elementos também são alterados. Além disso, estamos diante da questão da identidade: como estabelecer uma identidade entre personagens históricos e lendários quando não parece ser possivel nem mesmo estabelecê-la entre personagens pertencentes a versões de lendas diferentes?

Por fim, apresentamos um trecho do caderno 3958.4 que nos é bastante caro, no qual se encontra o desenvolvimento do que seria o funcionamento de um sistema semiológico e sua relação com a teoria do valor e a identidade:

- A lenda se compõe de uma série de símbolos <em um sentido a definir>

- Esses símbolos, sem que se duvide, estão submetidos às mesmas vicissitudes e às mesmas leis que todas as outras séries de símbolos, por exemplo, os símbolos que são as palavras da lingua

- Todos fazem parte da Semiologia.

16 No original: "[...] Exemple de la nulité Version a. - Le roi X, a 3 fils: Gunther, Gêrnôt et Gîselher. Ces fils ont un cousin Hagen. Version b. - Le roi X. a 3 fils: Gunther, Gêrnôt et Hagen. Sur quoi on va écrire: hagen a pris la place de Gîselher. Ou bien Gîselher est inconnu à [ II y a tout un monde dans cette simple façon (praen pratique presque inévitable de procéder. Rien ne preuve jusqu'ici <par avance> que le rôle de Hagen ne soit pas celui qu'a dans l'autre version Gunther, ou même qu'il n'yait un imbroglio tel etc. <qu'on ne pourrait pas dire d'une version à l'autre qui répond à un nom. > Au fait et au prendre: à comparer Qualité de frère fils de X. Individu a. Nom: Hagen Si la légende prend le casque de Dietrich <Achille> pour le mettre sur la tête de Sigfrid, la femme de Sigfrid pour la donner à Gunther, il n'y aura plus ni Dietrich ni Sigfrid. Or c'est ce qui arrive dans une mesure plus ou moins grande, et dans une mesure qu'il n'est permis à personne $[<L a$ question n'est pas de savoir s'il est probable que la légende le fasse. Elle est uniquement de constater que si elle le faisait, ou si elle le fait, nous sommes dans l'incapacité absolue même pour un casque de dire qu'il "s'agit » de la même personne, mais plus généralement que cette personne est en partie constitué par son casque.>". 
Não há nenhum método para supor que o símbolo deva permanecer fixo, nem que ele deva variar indefinidamente, ele deve, provavelmente, variar em certos limites.

A identidade de um símbolo não pode jamais ser fixada depois do instante que se torna símbolo, ou seja, inserido na massa social que lhe fixa a cada instante o valor.

Assim, a runa $\underline{Y}$ é um "símbolo".

SUa IDENTIDADE < parece algo tangivel, e quase ridiculo para melhor afirmar> consiste nisso: que ela tem a forma $\underline{Y}$, que ela se lê $\underline{Z}$, que ela é a oitava letra do alfabeto, que ela é chamada misticamente de Zann, enfim, que algumas vezes é citada como a primeira da palavra. Depois de algum tempo: ... ela é $10^{a}$ do alfabeto ... mas aqui ela já começa a supor uma unidade que [

Onde está agora a identidade? Respondemos, em geral, com um sorriso, como $<$ se isso fosse uma coisa de fato curiosa> ressaltar o lado filosófico da coisa, que não diz nada menos que todo símbolo, uma vez lançado em circulação-ora, qualquer símbolo só existe porque é lançado em circulação - está no mesmo instante na incapacidade absoluta de dizer em que consistirá sua identidade no instante seguinte.

$<$ Não apenas nós percebemos que seria necessário achar a identidade. Onde está realmente a identidade? Eu poderia muito bem dizer que isso é uma coisa incalculável, que seria em vão se nós tentássemos querer fundá-la em qualquer coisa> mesmo que seja em uma combinação de caracteres (SAUSSURE, Ms. Fr. 3958-4, tradução nossa) ${ }^{17}$.

Nessa perspectiva, é interessante nos perguntarmos como ficaria o objetivo histórico de Saussure ao lado do funcionamento desse sistema semiológico que é a lenda. Dado que a lenda é um sistema semiológico como a língua, é plausivel afirmar que seria possivel seguir suas mudanças através do tempo, por meio de uma análise diacrônica. Ademais, fica perceptível que o valor incide no funcionamento da lenda na mesma proporção que o faz na língua, a despeito de sua relação com a história. Assim, mesmo que a lenda dos Nibelungos tenha uma origem histórica no reino burgúndio, esse referente se perde a partir do momento em que a transmissão oral ocorre, principalmente considerando que essa transmissão se deu durante vários séculos. Nesse sentido, Saussure parece constatar que, na verdade, a história que ele busca não é a história propriamente dita, mas uma história afetada pelo funcionamento semiológico, uma história que é tocada pela língua e pela fala.

\footnotetext{
17 No original: "La légende se compose d'une série de symboles <dans un sens à préciser> - Ces symboles, sans qu'ils s'en doutent, sont soumis aux mêmes vicissitudes et aux mêmes lois que toutes les autres séries de symboles, par exemple les symboles qui sont les mots de la langue - Ils font tous partie de la sémiologie II n'y a aucune méthode à supposer que le symbole doive rester fixe, ni qu'il doive varier indéfiniment, il doit probablement varier dans certaines limites. L'identité d'un symbole ne peut jamais être fixée depuis l'instant où il est symbole, c'est-à-dire versé dans la masse sociale qui en fixe à chaque instant la valeur. Ainsi la une $Y$ est un « symbole ». Son IDENTITÉ <semble une chose tellement tangible, et presque ridicule pour mieux l'assurer> consiste en ceci: qu'elle a la forme $Y$; qu'elle se lit Z; qu'elle est la lettre numérotée huitième de l'alphabet; qu'elle est appelée mystiquement Zann, enfin quelquefois qu'elle est cité comme première du mot. Au bout de quelque temps: ... elle est la 10e de l'alphabet ... mais ici déjà ELLE commence à supposer une unité que [Où est maintenant l'identité ? On répond en général par sourire, comme <si c'était une chose en effet curieuse> remarquer la portée philosophique de la chose, qui ne va à rien moins que dire que tout symbole, une fois lancé dans la circulation - or aucun symbole n'existe que parce qu'il est lancé en circulation - est à l'instant même dans l'incapacité absolue de dire en quoi consistera son identité à l'instant suivant [<Non-seulement nous apercevons qu'il aurait fallu trouver l'identité. Où est réellement l'identité ? Je pourrais fort bien dire que ce qui est c'est chose bien plus incalculable, qu'il aurait été vain si nous l'avions essayé de vouloir la fonder sur quelque chose mais du même coup sur quoi que ce soit - même sur une combinaison de caractères>".
} 


\section{CONSIDERAÇões FINAIS}

Neste artigo, tivemos como objetivo pensar a noção de "margem" e "marginal" nas margens das elaborações saussurianas. Consideramos como "margens" os limites teóricos entre documentos e temas de naturezas distintas. No caso, analisamos documentos referentes às lendas germânicas e a teorização mitográfica neles encontrada, relacionando-a às elaborações linguísticas de Ferdinand de Saussure.

O desenvolvimento da argumentação nos leva a crer, como já defendido por outros autores, como Silveira (2007), Testenoire (2019) e Coelho (2019), que os diferentes domínios aos quais Saussure se dedicou durante sua vida acadêmica são complementares e não opositivos. Isso se sustenta, neste artigo, pela consideração de um pressuposto básico da teoria saussuriana: a linguagem é, por si mesma, heteróclita e a língua deve ser tomada como um princípio de classificação, o que implica a sua relação, a todo momento, com essa heterogeneidade.

Nesse sentido, falar de margens, como vimos, adquire uma nova conotação. Se a definição apresentada em nossa introdução era sinônima de "borda" e de "limite", as margens de uma teorização nos parecem mais como pontos de encontro e de pertencimento, em que há um movimento teórico de estabelecimento de um objetivo de estudo. Pensar a lingua é, de certa forma, pensar tudo aquilo que compõe a linguagem, pois as relações estabelecidas entre esses fenômenos são tão íntimas que, mesmo que haja uma separação epistemológica, ela não é definitiva.

Talvez a noção de terceira margem seja pertinente não só ao considerarmos as elaborações saussurianas, como também todos os estudos da linguagem. A terceira margem é o lugar em que a canoa se encontra, que apesar de ser, de certa forma, delimitado, ainda assim está em movimento e toda sorte de coisas passa ao seu redor.

\section{ON THE MARgins OF A THEORY: THE LANGUAGE AND GeRMANIC LEgENDS}

Abstract: In this article, we analyze the manuscripts on Germanic legends in order to question the classification of "marginal" given to these studies. For this, I start from a reflection on the nature of language in the saussurian theoretical framework and on the notion of "margin" in this context.

Keywords: Ferdinand de Saussure. Manuscripts. Germanic legends. Semiology. Language.

\section{REFERENCIAS}

AVALLE, D. S. La sémiologie de la narrativité chez Saussure. In: BOUAZIS, C.; AVALLE, D. S. Essais de la théorie du texte. Paris: Galillée, 1973. p. 17-49.

BOUQUET, S. Introdução à leitura de Saussure. São Paulo: Cultrix, 1997.

COELHO, M. P. Ferdinand de Saussure: entre a lingua e as linguas. 2019. Tese (Doutorado em Estudos Linguísticos) - Universidade Federal de Uberlândia, Uberlândia, 2019.

DE MAURO, T. Notes. In: SAUSSURE, F. de. Cours de Linguistique Générale. Paris: Éditions Payot er Rivages, 1967. p. 405-477. 
DICIONÁRIO Priberam da Língua Portuguesa, 2008-2020. Disponivel em: http:/ / www.priberam.pt/dlpo/chave. Acesso em: 5 maio 2020.

ENGLER, R. Sémiologies saussuriennes: 1. De l'existence du signe. Cahiers Ferdinand de Saussure. Revue suisse de linguistique générale. Genève: Librairie Droz S. A., n. 29, p. 45-73. Publicado por Cercle Ferdinand de Saussure, 1974-1975.

FEHR, J. Saussure: cours, publications, manuscrits, lettres et documents. Les contours de l'oeuvre posthume et ses rapports avec l'oeuvre publiée. Revue Histoire, Épistemologie et Langage, t. 18, f. 2, p. 179-199, 1996.

HENRIQUES, S. M. Os manuscritos de Ferdinand de Saussure sobre as lendas germânicas: uma relação entre a fala e a história. 2019. Tese (Doutorado em Linguística) - Universidade Estadual de Campinas, Campinas, 2019.

HERMAN, N. The development of the Nibelungen-legend in various periods of German literature. 119 f. Dissertation (Master) - Dalhousi University, Halifax, 1999.

MARCHESE, M. P. Une source retrouvée du Cours de Linguistique Générale de F. de Saussure. Cahiers Ferdinand de Saussure. Revue suisse de linguistique générale. Genève: Librairie Droz S. A., n. 56, p. 333-339. Publicado por Cercle Ferdinand de Saussure, 2003.

NORMAND, C. Saussure: uma epistemologia da linguística. In: SILVEIRA, E. M. (ed.). As bordas da linguagem. Uberlândia: EdUFU, 2011.

PROSDOCIMI, A. Sul Saussure dele leggende germaniche. Cahiers Ferdinand de Saussure. Revue suisse de linguistique générale. Genève: Librairie Droz S. A., n. 37, p. 35-106. Publicado por Cercle Ferdinand de Saussure, 1983.

REDARD, G. Deux Saussure? Cahiers Ferdinand de Saussure. Revue suisse de linguistique générale. Genève: Librairie Droz S. A., n. 32, p. 27-41. Publicado por Cercle Ferdinand de Saussure, 1978.

ROSA, G. A terceira margem do rio. In: ROSA, G. Primeiras Estórias. Rio de Janeiro: Nova Fronteira, 1988.

SAUSSURE, F. de. Curso de Linguística Geral. Editado por Charles Bally \& Albert Sechehaye com a colaboração de Albert Riedlinger. Tradução A. Chelini, J. P. Paes e I. Blikstein. 5. ed. São Paulo: Cultrix, 2012 [1916].

SAUSSURE, F. de. Recueil des publications scientifiques de Ferdinand de Saussure. Texte établi par Charles Bally e Léopold Gautier. Géneve: Payot/Droz, 1922 [1904], (p. np-631).

SAUSSURE, F. de. Ms. Fr. 3958. Bibliothèque de Genève.

SILVEIRA, E. As marcas do movimento de Saussure na fundação da linguística. Campinas: Mercado das Letras/Fapesp, 2007.

SILVEIRA, E. O lugar do conceito de fala na produção de Saussure. In: FIORIN, J. L.; FLORES, V. do N.; BARBISAN, L. B. (org.). Saussure: a invenção da linguística. São Paulo: Contexto, 2013.

STAROBINSKI, J. As palavras sob as palavras. São Paulo: Perspectiva, 1974.

TESTENOIRE, P. Y. A sombra do Curso (1960-1980). Leitura: novo retorno a Saussure, Maceió, v. 1, n. 62, p. 394-414, 2019.

ZILBERBERG, C. Une continuité incertaine: Saussure, Hjelmslev, Greimas. In: ZINNA, A. (éd.). Hjelmslevaujourd'hui. Turnhout: Brépols, 1997. p. 165-192. 